striking facts-and, it may be, a fundamental factor-is the lateral displacement-i.e., want of approximation of the laminæ vertebrales. In most cases of extroversio vesicæ the want of approximation of the two halves of the pelvio girdle is markedly existent, and has rendered possible the advantageous employment of Trendelenberg's operation of division of the sacro-iliac articulations.

I was convinced of the importance of the non-approximation in the case before me, and I therefore decided to follow out in its treatment the evident indication and to endeavour to bring about the approximation of the three bony portions of the upper jaw before attempting the union of the soft parts. The first method I adopted with this view was difficult and complicated in execution, and involved considerable disfigurement of the patient. Unfortunately, I on]y appreciated its disadvantages after $I$ had tried it on one side of the face. I had considered it necessary, before attempting to approximate the two superior maxillæ, to divide their principal bony attachments to the rest of the skull. I made my first trials on the dried skull of a child aged about two years. In order to assimilate the conditions as far as possible I sawed ont of the palate and alveolar process a portion corresponding to a complete palatal cleft. On the skull thus prepared the division of the nasal, zygomatic, and orbital processes was easily effected, and enabled me to completely approximate the artificially separated superior maxillæ. I then proceeded to carry out the same processes on $\mathrm{my}$ patient. I divided subcutaneously on the right side the zygomatic and external orbital processes without difficulty ; in attempting to divide the nasal process, however, I found it so greatly thickened and so resistent as to break the fine bone forceps with which I was working. I had a few anxious moments before I satisfied myself that the broken fragment of blade was left sticking in the nasal process and had not passed down the larynx. I then desisted from any further attempt to cut through this solid attachment and found, as might be expected, that the maxilla was in no ways more movable than before. I gave up the attempt for the time, having done so far no good and having produced a somewhat alarming bæmatoma of the lower eyelid. A month later I commenced again. I did not on this occasion attempt division of bony structures. I simply took a firm grip of the alveolar processes of the two superior maxillæ with the sharp points of a strong pair of forceps, shaped somewhat like a lion forceps, and with very considerable pressure, exerted with great care, at once brought together the two maxillæe along the greater part of the fissure, the only obstacle to their complete approximation being the interposed septum nasi. The snout was then forced down without difficulty to take up its position between the two maxillæ. A delta-metal wire was next passed round the three portions of the upper jaw. Posteriorly it stretched across from the last right premolar to the last left premolar, lying below the newly approximated palate. Laterally it lay on either maxilla in the groove between the gums and teeth anteriorly its ends were twisted together on the teeth carried by the inter-maxillary bone. The maxillæ being firmly held in their new position by the forceps, the wire was twisted up as tightly as possible, binding the three portions of the jaw firmly together. On removing the forceps the jaws sprang a little apart; but a new application of pressure and a further twist to the wire permanently fixed them so closely together that it was impossible to introduce a probe between them anywhere except at the apex of the inter-maxillary bone.

The child had absolutely no reaction after this operation and wore the wire comfortably for thirty-eight days, eating his ordinary meals after the first week. On the removal of the wire the bones retained their new positions absolntely, and a very simple plastic operation remained necessary to unite the skin and mucous membrane from the lip to the uvala. A series of photographs was taken at different stages of the operation; but, owing to the difficulty of sufficiently illuminating the oral cavity, none of them were suitable for reproduction. The experience of a single case is naturally useless as a basis for deductions, and the only opinions one is justified so far in expressing are : 1. That in some cases of fissure of the hard palate-especially, perhaps, in those in which the fissure is complete the non-approximation of the two maxillæ may be an important factor in the production of the gap. 2. That in such cases the approximation of the separated portions by forcible pressure may be possible. Such approximation is very simple in its performance, is not likely to be harmful in its results, and may greatly facilitate the subsequent operation for complete union of the soft parts. 3. It remains to be seen whether the forcible manipulation of the jaw is disadvantageous to its future development, and it may be that in some cases the approximation may entail so much deformity in the jaw as to greatly discount its possible advantages.

Cairo.

\section{NOTES ON THE CULTIVATION OF THE TETANUS BACILLUS AND OTHER BAC- TERIOLOGICAL METHODS.}

(From the Bacteriological Department, King's College, London.)

BY R. T. HEWLET'T, M.D., M.R.C.P. LOND., DEMONSTRATOR OF BACTERIOLOGY IN KING'S COLLEGE.

Cultivation of the tetanus bacillus.--In order to obtain the chemical products for inoculation and other purposes the bacillus of tetanus may be grown without the use of any complicated apparatus, in an atmosphere of hydrogen, in the following manner. "Yeast flasks" of about 90 c.c. capacity are made use of, and are filled three parts full with a 2 per cent. grape-sugar bouillon. The neck is corked with a perforated rabber cork (Fig. 1, A) through which a glass tube (B) passes to the bottom of the flask, projecting two inches above the rubber cork and here plugged with cottonwool. The lateral tube of the yeast flask (c) is also plugged with cotton-wool, care being taken that the plugs are loose enough to allow air to pass freely. The whole is sterilised and inoculated. The glass tube (B) which passes through the rubber cork is then connected with a Kipp's or other hydrogengenerating apparatus by means of a rubber tube, and a current of hydrogen is passed through the flask. The hydrogen bubbles through the bouillon and escapes by the lateral tube. After the gas has passed for about an hour a small capsule containing mercury (D) is applied to the end of the latera branch, so that the open end just dips below the surface of

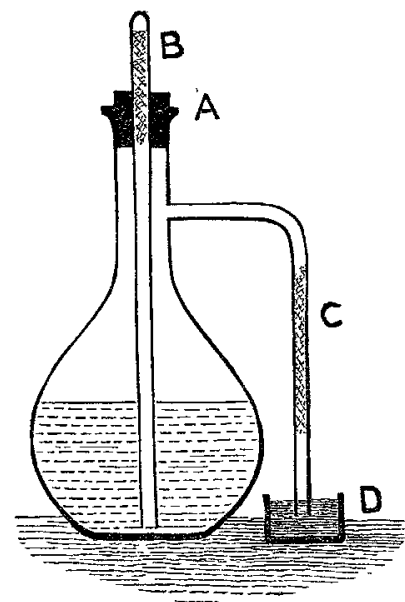

Fig.l.

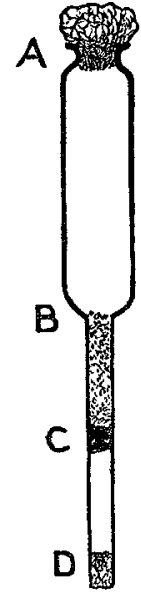

Fig.2. the mercury, and the tube (B) which passes through the rubber cork is sealed off in the blowpipe flame, care being taken that all the air has been expelled from the flask by a free current of hydrogen. The flask, with the capsule of mercury applied to the end of the lateral branch, can then be placed in the incubator. Thus the mercury forms a valve air cannot enter while gases formed by the growth of the organism have free exit.

Cultivation of anaerobic organisms in agar.-With a little care the bacillus of tetanus and other strictly anaerobic organisms can be grown with comparative ease in agar. It is well to employ a grape-sugar agar, ordinary agar with the addition of about 2 per cent. of grape-sugar, and narrow test-tubes filled three parts full with the medium. The tubes are steamed for a few minutes in the steam steriliser just before use, to get rid of as much dissolved oxygen as possible, and then cooled in cold water. When the agar has set, the inoculations are made well into the depth of the medium. The tube is then carefully warmed in the Bunsen burner so as to melt the superficial layer of the agar and seal the inoculation puncture. The npper part of the tube 
How heated to expel a portion of the air, and a well-fitting rubber cap is applied while the tube is still hot.

Agar plate cultivations.-Agar plate cultivations, as is well known, are somewhat difficult to make, but by employing the following expedient modified agar plates may be prepared which will answer most purposes. A tube of sterile nutrient agar is melted, poured into a sterilised Petri's dish resting on a level surface, and allowed to set. A suitable dilution of the material to be examined is made in some fluid mediumsterile broth, water, \&c. A few drops of this dilution are then poured over the sterile agar plate in the Petri's dish and allowed to run over the surface. The dish is placed in the incubator; the fluid soon evaporates, and the organisms are deposited on the surface of the agar and develop colonies. Several such modified plate cultivations should, of course, be prepared at the same time.

Staining sarcine and ascospores. - Professor Crookshank has long made use of the following method for staining sarcina, and none answers better. Cover-glasses are prepared in the ordinary way, care keing taken to spread the 1.m gently, so as to break up the sarcina formation as little as possible. After drying and fixing, the preparation is stained with Neelsen's solntion of fuchsin for two minutes, rinsed in water, and then rinsed in alcohol (methylated spirit) for a few seconds, quickly rinsed in water again, dried, and mounted in Canada balsam. If the alcohol acts for more than a few seconds the whole of the colour will be removed; if for too short a time the divisions between the celis will be indistinct. A little practice is needed to hit off the right point. The same method may be used for staining streptococci and many other bacteria, and is especially indicated when much debris is mixed with the organisms; this is readily decolourised, and clean preparations can be obtained. Sarcinz may also be stained in a similar manner, substituting Löfler's methylene blue solution for the Neelsen's fuchsin, and staining for fifteen roinutes, then rinsing in water, alcohol, \&c., as before. Exceedingly beautiful double-stained preparations of the ascospores of yeasts may be obtained by the following method. Cover glasses are prepared in the ordinary way and are stained with Neelsen's solution of fuchsin for two minutes, rinsed in water, decolourised in alcohol for half to one minute, until the spores only remain coloured, then rinsed in water, counter-stained with Löffler's blue for five minutes, washed, dried, and mounted in Canada balsam. The spores are stained red, the unaltered cells, \&c., blue.

Staining actinomyces.-The Ehrlich-Biondi reagent is an admirable stain for sections of actinomycosis. The best results have been obtained by staining in the solution for about half an hour, decolourising in alcohol for some time until the sections become brownish, and then clearing and mounting. Bovine actinomycosis thns treated shows the "clubs" stained brown and sometimes a "mycelial" network, within the ring of clubs, stained green. With this gtain the clubs could be readily demonstrated in sections of human actinomycosis, in which Gram's method failed to show them.

Examination of air.-Recently, for the bacteriological examination of air, Bedgwick's method has been made use of, and it seems to be the best of the many methods which have been suggested for this purpose. A glass tube of special form is employed. (Fig. 2.) This consists of an expanded portion (A B) about $15 \mathrm{~cm}$. long and $4.5 \mathrm{~cm}$. in diameter; one end of this is contracted so as to form a neck (A) $2.5 \mathrm{~cm}$. in diameter and in length; to the other end is fused a glass tube (B D) $15 \mathrm{~cm}$. long and $0.5 \mathrm{~cm}$. in diameter. The neck of the tube is plugged with cotton-wool, and two wool plugs are inserted in the narrow tube, one at its open end (D), the other about 6 to $8 \mathrm{~cm}$. from the wide part (C). The whole is then sterilised. When cool, the narrow part of the tube, from its origin at the wide part down to the first plug $(\mathrm{B} \mathrm{C})$, is filled with powdered cane sugar (No. 50, B.P. gauge), which has been carefully dried and sterilised at $120^{\circ}$ to $130^{\circ} \mathrm{C}$. The tube is again sterilised at $120^{\circ}$ to $130^{\circ}$ for two or three hours, the greatest care being taken not to melt the sugar. After sterilisation the tube is ready for use. The wool plug is removed from the mouth (A), and a measured volume of air is aspirated through the layer of powdered sugar by means of a small hand air-pump, the volume of air being measured by the displacement of water in a flask. Having taken the sample (5-20 litres), the wool plug is replaced in the neck (A). The powdered sugar is then shaken down into the wide part of the tube (A B), and 15 c.c. of melted sterile nutrient gelatine are poured in. The powdered sugar readily dissolves in the melted gelatine, and when solution is complete a roll-culture is made in the tube, just as in Esmarch's method. The tube is then placed in an incubator at $20^{\circ} \mathrm{C}$, and the colonies are allowed to develop.

King's College, W.C.

A CASE OF SERO-PURULENT CYST, PROBABLY OF THE RIGHT SEMINAL

\section{VESICLE. ${ }^{I}$}

Bx RAMON GUITÉRAS, M.D.,

INSTRUCTOR IS OPERATIVE SURGERY TO THE NEW YORK POST-GTRADUAT' MEDICAL SCHOOL, AND SURGEON TO THE NEW YORK CITY, FREYCH, AND COLUMBUS HOSPITALS.

A MAN twenty-four years of age presented himself at the French Hospital, New York City, on March 10th, 1894, complaining of a swelling in the lower abdomen. His previous history was as follows. Since he was twelve years of age, when he was confined to his bed for about one week with a fever, he had always enjoyed good health until last summer, when he was suddenly seized with a severe pain in the abdomen and chest, accompanied by a difficulty in breathing. The attack lasted but a short time, and was evidently due to indigestion. Since then he has had two other attacks of a similar nature. On Feb. 10th, about ten days after his last attack, he noticed a tumour about the size of an orange in the lower part of the abdomen pushing up from behind the pubes. This caused him no inconvenience, and would have been overlooked had it not been for the fact that it continued to increase in size. It grew to be as large as a cocoanut, and then larger, until it had obtained the size of an adult head. It then began to inconvenience him somewhat by giving rise to a heavy dragging feeling. His appetite began to fail, and although the functions of his various organs were intact, and the pressure of the tumour did not interfere with the powers of urination or defecation, he decided, nevertheless, to enter the hospital to see what could be done for him. On examining the tumour externally, inspection revealed a swelling about the size of a Rugby football extending up from, and out of, the pelvis, to a point above the umbilicus, closely resembling in form and outward appearance a gravid uterus in the seventh month of pregnancy. Its walls were very tense on palpation, and had an elastic feel. It was flat on percussion. My impression on first seeing him, as I could at that time obtain no history, the patient being unable to speak any other language than modern Greek, was that he had a largely dilated bladder and was suffering from retention of urine. I accordingly catheterised him, but could draw off only three ounces of urine in all, the tumour remaining the same. I then examined him bimanually-that is, with the finger of one hand in the rectum and the other hand on the abdomenand found the tumour wedged tightly down into the floor of the pelvis, conforming in shape with the pelvic cavity. The prostate and seminal vesicles could not be made out with any distinctness. A vibration was noticed like the wave transmitted from one side of an abdomen tensely dilated with fluid to the other, or through any other tensely dilated fluid tumour. On the following day he was examined with the cystoscope by Dr. J. R. Hayden and myself, and, while the left ureter secreted normally, the right one could not be brought into view. The tumour was then explored by means of an aspirating needle at several points, and specimens of fluid varying in colour and consistence were withdrawn, some being thin and clear, while others were thick and "pea-soupy." We examined them hastily, and found that they were all highly albuminous and contained pus. It, therefore, seemed probable that we had to do with a multilocular cystic tumour, arising possibly from a floating kidney which had become lodged in the pelvis. Accordingly an operation was decided upon, and on March 15th the patient was etherised, and an incision was made through the abdominal wall in the median line, four and a half inches in length, from the symphysis pubis towards the umbilicus. The abdominal wall having been cut through, we came to a pouch of a greyish-pink colour extending up from the pubis towards the umbilicus, about three and a half inches in length. It was shrivelled and corrugated, though not

1 Presented before the New York Society of Dermatology and Genitourinary Surgery, April 15th, 1894. 